\title{
KEAMANAN DAN KENYAMANAN TROTOAR DI TAMAN TINGKIR, KOTA SALATIGA
}

\author{
Yudhistira Adi Nugroho* \\ Magister Arsitektur, Fakultas Teknik, Universitas Udayana, \\ yudhistira.nugroho@ymail.com
}

\begin{abstract}
ABSTRAK
Trotoar adalah salah satu bentuk sarana bagi pejalan kaki yang sangat dibutuhkan untuk menunjang keamanan dan kenyamanan masyarakat dalam melakukan aktifitasnya sehari-hari sebagai alternatif menuju tempat tujuan. Trotoar dalam penelitian kali ini akan fokus pada trotoar yang ada di area Taman Tingkir kota Salatiga. Tujuan dari penelitian ini adalah untuk mengetahui apakah trotoar di Taman Tingkir ini aman dan nyaman baik dari segi fisik, pengguna, dan pemanfaatan trotoar, serta pendapat dari para pejalan kaki sebagai penggunanya. Metode yang digunakan dalam penelitian ini adalah kombinasi dari metode penelitian evaluasi dan metode penelitian deskriptif kualitatif yang mengacu pada studi kuantitatif. Data dikumpulkan dengan cara observasi, kuesioner, wawancara dan studi kepustakaan. Pemilihan responden mengunakan teknik nonprobability sampling dengan cara pengambilan sampel accidental sampling dan purposive sampling. Jumlah responden kuesioner sebanyak 60 orang. Data fisik trotoar akan dianalisis menggunakan metode analisis komparatif. Sedangkan untuk data kuesioner akan dianalisis menggunakan metode analisis pembobotan. Data kuesioner ini nantinya akan diperkuat dengan hasil data wawancara kepada para pejalan kaki. Hasil penelitian menunjukan bahwa sebenarnya dari segi fisik, trotoar di Taman Tingkir masuk dalam kategori aman dan nyaman karena sudah sesuai dengan standar-standar ketentuan trotoar yang telah ditetapkan oleh pemerintah. Namun karena adanya penyalahgunaan fungsi trotoar yaitu sebagai tempat pedagang kaki lima, dan penyewaan mainan anak serta ditambah lagi dengan digunakannya area pembatas jalan dengan trotoar sebagai tempat parkir liar, trotoar Taman Tingkir menjadi tidak aman dan nyaman. Penyalahgunaan fungsi trotoar ini selain berpengaruh kepada keamanan dan kelancaran sirkulasi pengguna jalan, juga mengganggu kebersihan serta merusak keindahan trotoar di Taman Tingkir kota Salatiga.
\end{abstract}

Kata kunci - : trotoar, pejalan kaki, keamanan dan kenyamanan

\begin{abstract}
A sidewalk is a means for pedestrians which is needed to increase safety and convenience for the society in doing their everyday tasks as an alternative means of transportation. The sidewalk which will be the base of this research are the sidewalks around the Tingkir park area, Salatiga. The purpose of this research is to find out whether or not the sidewalks around Tingkir park are safe and Convenient both in terms of physical, user, and sidewalk utilization. The method which will be used in this research is a combination of evaluative and qualitative methods which refers to quantitative studies. Data is collected via observation, questionnaire, interviews, and literature study. The respondents are selected using nonprobability technique by sampling using accidental sampling and purposive sampling. The number of questionnaire respondents is 60 people. Physical sidewalk data will be analysed using comparative methods. Sa for the questionnaires will be analysed using weighting analysis method. Questionnaire data will later be supported by interview data from the pedestrians. Research suggests that from a physical perspective, the sidewalks around Tingkir park area is regarded as a worthy of being included in the safe and convenient category because it has followed the sidewalk standards set by the government. However, due to misuse of the sidewalk, such as street vendors, and rental of toys, and also the road marking areas are used for illegal parking, the sidewalks at Tingkir
\end{abstract}


park are not save and convenient, misuse of the sidewalks not only effects the safety and smooth circulation of road users, but also effects cleanliness negatively and also disrupts the beauty of the sidewalks at Tingkir park, Salatiga.

Keywords - : sidewalk, pedestrians, safety and convenience

\section{PENDAHULUAN}

Trotoar adalah salah satu bentuk jalur pedestrian, yaitu bagian dari jalan berupa jalur terpisah khusus untuk pejalan kaki. Fungsi jalur tersebut adalah untuk meningkatkan kelancaran, keamanan, dan kenyamanan bagi pejalan kaki pada waktu bergerak dari satu tempat ke tempat lain. Trotoar juga dapat memicu interaksi sosial antar masyarakat apabila berfungsi sebagai suatu ruang publik.

Menurut Gunawan (1988), trotoar umumnya ditempatkan sejajar dengan jalur lalu lintas, dan harus terpisah dari jalur lalu lintas oleh struktur fisik. Pengertian tersebut mengatakan bahwa antara trotoar merupakan tempat berjalan kaki yang berada bersebalahan dengan jalan raya, keadaan trotoar dan jalan raya harus memiliki batas yang memisahkan keduanya. Pemisah yang dibuat tersebut digunakan untuk keamanan pejalan kaki agar pemakai jalan raya tidak memasuki wilayah trotoar dan dapat membahayakan pejalan kaki.

Dari dua pengertian di atas dapat disimpulkan bahwa trotoar merupakan salah satu bentuk pedestrian yang berada di pinggir jalan dan memiliki ketinggian tertentu serta terpisah dari jalur lalu lintas oleh struktur fisik. Dapat dikatakan bahwa segala sesuatu bangunan yang berada di trotoar tidak diperkenankan karena tidak sesuai dengan fungsi dan tempatnya.

Namun kelancaran dan kenyamanan para pengguna trotoar saat ini mulai terganggu karena disalahgunakan dan banyak mengalami perubahan, baik fisik maupun fungsi. Sebagai contoh, penyalahgunaan trotoar terjadi di Taman Tingkir kota Salatiga. Sejak selesai dibangun di tahun 2015, Taman Tingkir mulai ramai dikunjungi oleh masyakarat baik masyarakat yang tinggal di sekitar area taman maupun masyarakat kota Salatiga secara umumnya. Namun, meningkatnya kunjungan ke Taman Tingkir ini juga dibarengi dengan meningkatnya pedagang kaki lima (PKL) yang berjualan di sekitaran area taman. Karena tidak tersedia area khusus PKL untuk berjualan, mereka memanfaatkan trotoar sebagai tempat untuk mendirikan kios-kios semi permanent untuk tempat berjualan. Dari PKL yang berjualan makan, minum, hingga yang menyewakan mainan untuk anak-anak seperti mobil-mobilan dan odongodong semuanya ada di area trotoar Taman Tingkir.

Penyalahgunaan trotoar di Taman Tingkir tidak berhenti pada keberadaan PKL saja. Ruang bebas antara trotoar dan jalan yang awalnya dimaksudkan sebagai area vegetasi dan peningkatan keamanan pejalan kaki, saat ini digunakan untuk tempat parkir kendaraan. Padahal disisi sebelah barat taman sudah 
disediakan area parkir kendaraan yang luas dan mudah dijangkau.

Pihak pengelola taman telah berusaha untuk mengembalikan fungsi trotoar sebagaimana mestinya. Mereka sudah memberikan peringatan dari yang halus hingga tegas kepada para PKL agar tidak berjualan di area trotoar. Para pengunjung yang parkir sembarangan pun sudah dihimbau untuk memarkir kendaraannya di area parkir yang sudah disediakan. Namun sepertinya usaha dari pihak pengelola ini sia-sia, penyalahgunaan trotoar masih terjadi hingga saat ini.

Penyalahgunaan trotoar di Taman Tingkir ini secara otomatis berdampak pada keamanan serta kenyamanan pejalan kaki sebagai pengguna trotoar. Berdasarkan pengamatan awal, tidak sedikit pejalan kaki yang turun ke bahu jalan karena terhalangi oleh keberadaan PKL dan parkir liar kendaraan. Bahkan tidak sedikit pula pejalan kaki yang secara tidak sengaja tertabrak oleh anak-anak yang sedang bermain mobil-mobilan di atas trotoar.

Berdasarkan permasalahan diatas, menjadi penting untuk diteliti tentang bagaimana keamanan dan kenyamanan trotoar di Taman Tingkir kota Salatiga. Diharapkan dari hasil penelitian ini dapat menjadi sebuah masukan bagi Pemerintah Kota Salatiga khususnya Dinas Lingkungan Hidup sebagai pihak pengelola taman dalam membenahi permasalahan keamanan dan kenyamanan trotoar di Taman Tingkir ini.

\section{Pembatasan dan Fokus Penelitian}

Beberapa pembatasan dan fokus penelitian ini ialah :
1. Penelitian ini meskipun mengkaji pedestrian secara umum, namun pembahasan akan lebih terfokus pada trotoar sebagai bagian dari pedestrian itu sendiri. Hal ini dimaksudkan agar peneliti dapat lebih intens melakukan pengamatan dan analisis selanjutnya.

2. Trotoar yang akan di kaji dalam penelitian ini hanya terfokus pada trotoar berada di area Taman Tingkir kota Salatiga dengan panjang trotoar \pm 422 meter.

3. Untuk responden penelitian akan fokus kepada pengguna trotoar yang merupakan masyarakat sekitar taman, dan pengunjung taman yang memiliki keadaan fisik normal, bukan pada penyandang disabilitas. Sehingga penelitian ini akan mengabaikan terkait standart keamanan dan kenyamanan trotoar bagi penyandang disabilitas.

4. Keamanan yang dimaksud dalam penelitian ini fokusnya pada keamanan gerak ketika berjalan diatas trotoar. Sedangkan kenyamanan yang dimaksud dalam penelitian kali ini akan terfokus juga pada kenyamanan gerak ketika berjalan diatas trotoar.

\section{Pedestrian dalam Konteks Perancangan Kota}

A. Pengertian Pedestrian

Pedestrian berasal dari bahasa Yunani pedos yang berarti kaki. Pedestrian juga berasal dari bahasa Latin pedesterpedestris yaitu orang yang berjalan kaki atau pejalan kaki, sehingga pedestrian dapat diartikan sebagai pejalan kaki atau orang yang berjalan kaki. Secara harafiah, pedestrian berarti "person walking in the street", yang berarti orang yang berjalan di jalan. 
Pejalan kaki adalah orang yang melakukan perjalanan dari suatu tempat / asal (origin) tanpa kendaraan, untuk mencapai tujuan atau tempat (destination) atau dengan maksud lain. Jalan merupakan media diatas bumi yang memudahkan manusia dalam tujuan berjalan, maka pedestrian dalam hal ini memiliki arti pergerakan atau perpindahan orang atau manusia dari satu tempat sebagai asal (origin) ke tempat lain sebagai tujuan (destination) dengan berjalan kaki (Rubenstein, 1992).

\section{B. Jalur Pejalan Kaki}

Ditinjau dari posisinya terdapat 2 (dua) jenis jalur pedestrian yaitu jalur pejalan kaki di dalam bangunan (berupa koridor dan tangga bangunan) dan jalur pejalan kaki diluar bangunan. Mengenai jalur pejalan kaki di luar bangunan terdapat beberapa jenis menurut fungsi dan bentuknya. Menurut fungsinya berupa :

- Trotoar yaitu bagian dari jalan berupa jalur terpisah khusus untuk pejalan kaki, biasanya terletak bersebelahan di sepanjang jalan, Fungsi jalur tersebut adalah untuk kenyamanan pejalan kaki pada waktu bergerak dari satu tempat ke tempat lain.

- Jalan setapak adalah suatu jalur khusus untuk pejalan kaki yang sangat sempit, lebarnya hanya cukup untuk satu orang pejalan kaki.

- Penyeberangan, digunakan pejalan kaki untuk menyeberang secara aman.

- Mall dan plaza, adalah suatu jalur pejalan kaki yang lebih berfungsi rekreatif. Bentuknya lebih luas daripada trotoar, mall biasanya dikaitkan dengan fungsi pembelanjaan, sedang plaza dikaitkan dengan fungsi rekreasi taman.

\section{Standar Ruang Trotoar}

\section{A. Lebar Trotoar}

Menurut Rubenstein (1987), ukuran dan lebar trotoar tergantung pada kapasitas skala dan hubungan terhadap elemen lainnya yang dikelompokkan :

- Sidewalk rata-rata $1,5 \mathrm{~m}$ diharapkan bisa untuk kursi roda. Sidewalk dibedakan dari 2,4 m ke 3,6 $\mathrm{m}$ di luar peruntukan kendaraan, dan volume pemakaian dilakukan seperlunya.

- Plaza atau mall, diperlukan sampai $12 \mathrm{~m}$ atau lebih untuk dapat menampung sirkulasi.

Tabel 1. Standar lebar minimum trotoar berdasarkan fungsi kawasan

\begin{tabular}{c|c|c}
\hline No & Lokasi Trotoar & $\begin{array}{c}\text { Lebar } \\
\text { Minimum }\end{array}$ \\
\hline 1 & $\begin{array}{l}\text { Jalan di daerah perkotaan atau kaki } \\
\text { lima }\end{array}$ & 4 meter \\
\hline 2 & Wilayah perkantoran utama & 3 meter \\
\hline 3 & Wilayah industri & 3 meter \\
& $-\quad$ Jalan primer & 2 meter \\
\hline 4 & $-\quad$ Jalan akses & 2.75 meter \\
& $-\quad$ Jilayah permukiman & 2 meter \\
\hline \multicolumn{2}{|c|}{ Jum primer }
\end{tabular}

Tabel 2. Standar lebar minimum trotoar berdasarkan jumlah pejalan kaki

\begin{tabular}{l|l|l} 
No & Jumlah Pejalan Kaki per detik per & Lebar Trotoar
\end{tabular}




\begin{tabular}{c|c|c}
\hline & meter & \\
\hline 1 & 6 orang & $2.30-5.00$ \\
\hline 2 & 3 orang & $1.50-2.30$ \\
\hline 3 & 2 orang & $0.90-1.50$ \\
\hline 4 & 1 orang & $0.60-0.90$ \\
\hline
\end{tabular}

Sumber: Keputusan Menteri Perhubungan No.KM.65 tahun 1993

Selain menggunakan tabel diatas dalam keadaan ideal untuk mendapatkan lebar minimum jalur pejalan kaki (W) menurut pedoman perencanaan jalur pejalan kaki pada jalur jalan umum No.032/T/BM/1999 dipakai rumus sebagai berikut :

$$
\begin{aligned}
& \mathbf{W}=\mathbf{V} / 35+\mathbf{N} \quad \mathrm{W}=\text { lebar jalur pejalan kaki (meter) } \\
& \mathrm{V}=\text { volume pejalan kaki } \\
& \text { (orang/menit/meter) } \\
& \mathrm{N}=\text { lebar tambahan sesuai keadaan } \\
& \text { setempat (meter) }
\end{aligned}
$$

\section{B. Tinggi Kereb (Elevation Uptrade)}

Berdasarkan pedoman teknik tentang persyaratan aksesibilitas pada jalan umum No.22/T/BM/1999 spesifikasi kereb menurut ketentuan, tinggi kereb cukup bervariasi dari $5 \mathrm{~cm}$ hingga $30 \mathrm{~cm}$. Dalam penelitian ini akan diambil standart kereb yang umumnya dipakai dengan tinggi $30 \mathrm{~cm}$, akan tetapi tinggi tersebut belum dikurangi dengan dalamnya kereb akan masuk kedalam tanah. Untuk itu mengacu juga dari standar tinggi tangga menurut petunjuk perencanaan trotoar No. 007/T/BNKT/1990 yang dikeluarkan oleh Dirjen Bina Marga, tinggi anak tangga disyaratkan maksimum $15 \mathrm{~cm}$ dan tinggi kereb terpasang adalah $25 \mathrm{~cm}$ dengan kedalaman kereb yang masuk sekitar $5 \mathrm{~cm}$, maka diasumsikan tinggi kereb yang akan menjadi parameter dalam penelitian ini memiliki tinggi pada kisaran $15-20 \mathrm{~cm}$.

\section{Ruang Bebas Trotoar}

Tinggi bebas trotoar tidak kurang dari 2,5 meter sesuai dengan standart ruang bebas menurut petunjuk perencaan Trotoar No.007/T/BNKT/ 1990 dan kedalaman bebas trotoar tidak kurang dari satu meter dari permukaan trotoar. Kebebasan samping trotoar tidak kurang dari 0,3 meter.

\section{Fasilitas/Street Furniture diatas Trotoar}

Mengacu dari tata cara perencanaan fasilitas pejalan kaki di kawasan perkotaan No. 011/T/Bt/1995 yang dikeluarkan oleh Dirjen Bina Marga maka fasilitas street furniture perjalan kaki terdiri atas :

- Tiang lampu penerang

- Tiang lampu lalu lintas

- Rambu lalu lintas

- Kotak surat

- Keranjang sampah

- Tanaman peneduh

- Pot bunga

\section{E. Permukaan dan Tekstur Material Penutup Trotoar}

Pengaturan penggunaan material penutup pedestrian yang bertekstur licin buatan dan kontras akan mengurangi kenyamanan gerak bagi pejalan kaki karena rentang tersandung dan terpeleset. Penutup pedestrian dengan tekstur licin sebaiknya dihindari, pada jalur pedestrian yang menurun (ramp) sebaiknya digunakan gradasi tekstur yang sesuai peruntukannya. 


\section{Faktor Keamanan Pedestrian}

Menurut Maslow (1968) ketika kebutuhan fisiologis telah terpenuhi maka akan muncul kebutuhan akan keamanan. Diantaranya; physical security (aman dari kejahatan dan agresi), security of employment (keselamatan kerja), security of revenues and resources (keamanan sumber daya), moral and physiological security (keamanan fisiologis), familial security (keamanan keluarga), security of health (keamanan kesehatan), dan security of personal property against crime (keamanan kekayaan pribadi dari kejahatan). Keamanan Pejalan kaki yang dimaksud adalah keamanan untuk bergerak atau berpindah dari satu ruang ke ruang berikutnya tanpa menimbulkan kecelakaan. Sehingga keamanan tersebut masuk dalam security of employment (keselamatan kerja) dan security of revenues and resources (keamanan sumber daya).

Menurut Hakim (2006) keamanan merupakan masalah terpenting, karena ini dapat mengganggu dan menghambat aktivitas yang akan dilakukan. Keamanan bukan saja berarti dari segi kejahatan (kriminal), tapi juga termasuk kekuatan konstruksi, bentuk ruang dan kejelasan fungsi.

Menurut Unterman (1984), keamanan adalah faktor utama bagi pengguna pedestrian yang merasa aman dengan adanya elemen-elemen pengaman dalam hal ini untuk melindungi pejalan kaki dari berbagai permasalahan yang timbul di jalur pedestrian.

\section{Faktor Kenyamanan Pedestrian}

Menurut Rustam Hakim dan Hardi Utomo (2003 : 185) kenyamanan adalah segala sesuatu yang memperlihatkan penggunaan ruang secara sesuai dan harmonis, baik dengan ruang itu sendiri maupun dengan berbagai bentuk, tekstur, warna, simbol mapun tanda, suara dan bunyi, kesan, intensitas, dan warna cahaya ataupun bau, atau lainnya. Hakim dan Utomo (2003 : 186) mengemukakan bahwa faktor-faktor yang mempengaruhi kenyamanan yaitu :

\section{A. Sirkulasi}

Jalan berperan sebagai prasarana lalu lintas dan ruang transisi (transitional space), selain itu juga tidak tertutup kemungkinan sebagai ruang beraktivitas (activity area) yang merupakan sebagai ruang terbuka untuk kontak sosial, wadah kegiatan, rekreasi, dan bahkan untuk aktifitas perekonomian masyarakat. Untuk itu diperlukan penataan ruang yang fungsionalis demi terciptanya kelancaran masing-masing aktifitas sirkulasi.

\section{B. Iklim atau Kekuatan Alam}

Salah satu kendala iklim yang muncul adalah curah hujan, faktor ini tidak jarang menimbulkan gangguan terhadap aktifitas para pejalan kaki. Oleh karena itu perlu disediakan tempat berteduh jika terjadi hujan, seperti shelter dan gazebo. Selain curah hujan, juga harus diperhatikan perlunya perlindungan terhadap radiasi sinar matahari. Radiasi ini mampu mengurangi rasa nyaman terutama pada daerah tropis seperti kota Salatiga.

\section{Kebisingan}


Tingginya tingkat kebisingan suara kendaraan bermotor yang lalu lalang juga menjadi masalah vital yang dapat mengganggu kenyamanan bagi pejalan kaki. Oleh sebab itu untuk meminimalisir tingkat kebisingan yang terjadi, perlu dilakukan penanaman pohon dengan pola dan ketebalan yang rapat serta tersusun teratur sebagai barier kebisingan.

\section{Aroma atau Bau-bauan}

Aroma atau bau-bauan yang tidak sedap bisa terjadi karena beberapa sebab seperti bau yang keluar dari asap knalpot kendaraan, atau bak-bak sampah yang kurang terurus yang tersedia di sepanjang pinggir trotoar. Selain itu, kadang terdapat areal pembuangan sampah yang tidak jauh dari daerah perlintasan jalan, maka bau yang tidak menyenangkan akan tercium oleh para pengguna jalan.

\section{E. Bentuk}

Bentuk elemen landscape furniture harus disesuaikan dengan ukuran standar manusia agar skala yang dibentuk mempunyai rasa nyaman (Hakim dan Utomo, 2003 : 190). Seringkali ditemui bahwa trotoar-trotoar yang telah disediakan tidak mempunyai pembatas yang jelas (kereb) dengan jalur kendaraan bermotor sehingga mengakibatkan jalur trotoar menjadi dimanfaatkan untuk lahan parkir-parkir liar dan sirkulasi kendaraan bermotor.

\section{F. Keamanan}

Untuk keamanan, trotoar harus dibuat terpisah dari jalur lalu lintas kendaraan. Selain itu, pemanfaatan trotoar sebagaimana fungsinya menjadi sangat penting bagi keamanan pejalan kaki. Peralihan fungsi trotoar menjadi berbagai aktifitas lain seperti PKL dan parkir liar sangat mengganggu dan membahayakan pejalan kaki karena trotoar tidak bisa dimanfaatkan secara optimal, sehingga tidak sedikit pejalan kaki yang terpaksa berjalan di bahu jalan.

\section{G. Kebersihan}

Trotoar yang terjaga kebersihannya akan memberikan daya tarik tersendiri. Untuk memenuhi kebersihan trotoar, perlu disediakan bak-bak sampah sebagai elemen lansekap dan saluran drainase yang terkonsep baik.

\section{H. Keindahan}

Keindahan mencakup persoalan kepuasan batin dan panca indera manusia. Untuk memperoleh kenyamanan yang optimal maka keindahan harus dirancang dengan meperhatikan dari berbagai aspek, baik itu aspek bentuk, warna, komposisi susunan tanaman, dan elemen perkerasan, serta diperhatikan juga faktor-faktor pendukung sirkulasi kegiatan manusia.

Mengacu pada kajian pustaka yang telah dibahas diatas, ditentukan indikator yang akan digunakan sebagai kriteria penilaian dalam penelitian ini adalah :

a. Faktor Keamanan

- Lebar trotoar

- Tinggi kereb/cansten pada trotoar, tinggi yang diambil pada kisaran $15-20 \mathrm{~cm}$ 
- Tinggi ruang bebas trotoar yang tidak kurang dari 2,5 meter.

- Permukaan dan tekstur material penutup trotoar (licin atau tidak).

Keamanan bukan saja berarti dari segi kejahatan (kriminal) tapi juga termasuk kekuatan konstruksi, bentuk ruang dan kejelasan fungsi. Pernyataan tersebut diterjemahkan ke dalam keamanan yang dimaksud dalam penelitian kali ini yang akan terfokus pada keamanan gerak ketika berjalan diatas trotoar.

\section{b. Faktor Kenyamanan}

- Kelancaran sirkulasi pejalan kaki

- Ketersediaan tempat berteduh baik dari hujan maupun sinar matahari

- Ketersediaaan barier kebisingan dari polusi suara lalu lintas

- Kebersihan trotoar yang terkait terhadap pembersihan rutin, tersedianya fasilitas bakbak sampah, dan saluran drainase yang terkonsep dengan baik

- Keindahan trotoar

- Fasilitas/street furniture diatas trotoar

\section{METODOLOGI}

\section{Metode Penelitian}

Metode penelitian yang digunakan dalam penelitian ini adalah kombinasi dari metode penelitian evaluasi dan metode penelitian deskriptif kualitatif yang mengacu pada studi kuantitatif. Metode evaluasi dalam penelitian ini bertujuan untuk mengevaluasi kondisi fisik trotoar yang ada apakah sudah sesuai dengan standar keamanan dan kenyamanan yang telah ditentukan. Hasil evaluasi ini nantinya akan dikaitkan dengan studi kuantitatif yang bertujuan untuk menganalisa tentang keamanan dan kenyamanan trotoar di Taman Tingkir kota Salatiga. Hasil analisa ini juga akan diperkuat dengan wawancara mendalam kepada para pejalan kaki.

\section{Lokasi Penelitian}

Penelitian ini dilakukan di trotoar yang terdapat di area Taman Tingkir kota Salatiga. Taman Tingkir masuk dalam wilayah administrasi Kecamatan Tingkir tepatnya di Kelurahan Sidorejo Kidul. Lokasi trotoar yang akan diteliti memiliki panjang trotoar \pm 422 meter.

Gambar 1. Peta Taman Tingkir kota Salatiga

Sumber: Detail Engineering Design (DED) Taman Tingkir, 2014 


\section{Jenis dan Sumber Data}

Jenis data dalam penelitian ini terdiri dari data kualitatif dan kuantitatif. Data kualitatif yang dikumpulkan adalah : kondisi existing trotoar Taman Tingkir meliputi kondisi fisik, penguna (civity), dan pemanfaatannya (activity). Data kuantitatif yang dibutuhkan adalah hasil kuesioner mengenai persepsi pejalan kaki terhadap keamanan dan kenyamanan trotoar di Taman Tingkir kota Salatiga.

Data bersumber dari data primer dan data sekunder. Sumber data primer adalah data yang diperoleh atau dikumpulkan secara langsung dari trotoar Taman Tingkir. Untuk mendapatkan data primer, harus dilakukan pengumpulan secara langsung di lapangan. Teknik yang dilakukan untuk mengumpulkan data primer antara lain adalah observasi, dokumentasi, wawancara, dan penyebaran kuesioner. Sumber data sekunder adalah data yang diperoleh atau dikumpulkan dari berbagai sumber litelatur mengenai teori maupun penelitian sejenis. Data sekunder juga dapat diperoleh dari instansi pemerintah terkait seperti Dinas Tata Kota, Dinas Cipta Karya, Dinas Lingkungan Hidup, dan lain-lain.

\section{Instrumen Penelitian}

Instrumen dan alat yang digunakan dalam penelitian ini adalah :

- Gambar Detail Engineering Design (DED) Taman Tingkir tahun 2014

- Alat tulis, kamera, voice recoder, meteran, perangkat komputer

- Kuesioner tertutup (closed ended question)
- Panduan wawancara

\section{Teknik Pengumpulan Data}

\section{a. Observasi}

Pengumpulan data secara langsung di trotoar Taman Tingkir untuk memperoleh data fisik, pengguna dan pemanfaatan. Pengumpulan data fisik meliputi lebar trotoar, tinggi kereb, tinggi bebas trotoar, jenis material penutup trotoar, dan jenis serta jumlah fasilitas/street furniture diatas trotoar. Untuk pengumpulan data pengguna dilakukan dengan pencatatan jumlah pejalan kaki yang melintas di lokasi penelitian. Proses pengamatan dilakukan selama 1 jam pada periode ramai pengujung, yaitu Pukul 08.00-09.00 WIB, 13.0014.00 WIB, dan 17.00-18.00 WIB. Proses pencatatan jumlah pejalan kaki membutuhkan waktu selama 1 (satu) hari. Dan observasi terakhir dilakukan dengan cara pengamatan langsung di lokasi penelitian untuk melihat pemanfaatan apa saja yang terjadi di trotoar Taman Tingkir.

\section{b. Kuesioner}

Akan dilakukan penyebaran kuesioner kepada beberapa respoden yang merupakan pejalan kaki untuk mengetahui pendapat mereka terhadap keamanan dan kenyamanan trotoar di Taman Tingkir Kota Salatiga. Pemilihan responden mengunakan teknik nonprobability sampling dengan cara pengambilan sampel accidental sampling dan purposive sampling. Jumlah responden kuesioner sebanyak 60 orang yang terdiri dari 30 orang pejalan kaki yang rutin lewat dan 30 orang pejalan kaki yang baru pertama kali atau 
jarang lewat di trotoar Taman Tingkir. Jumlah ini dinilai sudah cukup untuk mewakili pejalan kaki di trotoar Taman Tingkir. Hal ini dilakukan karena jumlah pejalan kaki di trotoar Taman Tingkir tidak tetap setiap harinya, sehingga mempersulit peneliti untuk melakukan perhitungan jumlah sampel menggunakan Rumus Slovin.

\section{c. Wawancara}

Wawancara ini digunakan untuk memperkuat hasil data dari metode kuesioner. Metode ini dipakai untuk memberikan pertanyaan dan juga untuk memperoleh masukan dari para pejalan kaki di trotoar Taman Tingkir.

\section{d. Studi Kepustakaan}

Dilakukan untuk menghimpun informasi dari peraturan-peraturan dan ketetapan-ketetapan yang telah dibuat oleh pemerintah tentang trotoar. Data ini nantinya akan digunakan untuk mengevaluasi kondisi fisik trotoar Taman Tingkir.

\section{Analisis Data}

Terdapat 2 (dua) tahapan dalam analisis data yaitu :

1. Analisis Komparatif

Hasil data fisik trotoar yang diperoleh dari obeservasi lapangan nantinya akan dikaitkan dengan standarstandar keamanan dan kenyamanan trotoar yang telah ditetapkan oleh pemerintah. Hal ini bertujuan untuk melihat apakah fisik trotoar Taman Tingkir sudah sesuai dengan peruntukannya atau tidak.

2. Analisis Pembobotan
Hasil data yang sudah terkumpul dari kuesioner tentang keamanan dan kenyamanan trotoar di Taman Tingkir kota Salatiga akan dianalisis dengan pembobotan Skala Likert dengan pembobotan nilai dan presentase nilai sebagai berikut:

Tabel 3. Tabel Bobot Nilai

Tabel Bobot Nilai

Sangat Tidak Baik (STB) 1

Tidak Baik (TB) 2

Baik (B) 3

Sangat Baik (SB) 4

Interval Presentase Nilai $=100 \% /($ Nilai Tertinggi $/$ Nilai Terendah)

$$
\begin{array}{ll}
= & 100 \% /(4 / 1) \\
= & 100 \% / 4 \\
= & 25 \%
\end{array}
$$

Tabel 4. Tabel Presentase Nilai

Tabel Presentase Nilai

$0 \%-24.99 \% \quad$ Sangat (Tidak Baik, Buruk, atau Tidak Aman dan Nyaman)

25\%-49.99\% Tidak Baik, Tidak Aman dan Nyaman

50\%- $74.99 \%$ Baik, Aman dan Nyaman

$75 \%-100 \% \quad$ Sangat (Baik, Bagus, atau Aman dan Nyaman)

Indikator yang menjadi patokan dalam penyusunan pernyataan-pernyataan dalam kuesioner adalah teori dan ketentuan-ketentuan tentang keamanan dan kenyamanan trotoar yang sebelumnya sudah dijelaskan dalam kajian pustaka.

\section{HASIL DAN PEMBAHASAN}


1. Hasil Observasi Fisik, Pengguna, dan Pemanfaatan

\section{Hasil Data Fisik}

Setelah dilakukan pengukuran dan pengamatan terhadap kondisi fisik trotoar, didapatkan hasil sebagai berikut :

Tabel 5. Tabel data fisik trotoar Taman Tingkir

$\begin{array}{llll}\text { No Indikator } & \text { Hasil Pengukuran } & \\ \text { Pengamatan } & & \\ 1 & \text { Lebar Trotoar } 3.1 \text { meter } & \\ 2 & \text { Tinggi Kereb Trotoar } & 0.2 \text { meter } \\ 3 & \text { Tinggi Bebas Trotoar } & >2.5 \text { meter } & \\ 4 & \text { Material Penutup Trotoar } & \text { Primer : Batu }\end{array}$

Andesit Bakar (tidak licin)

Sekunder : Koral Sikat (tidak licin)

5 Fasilitas/street furnitureTrotoar Rambu

Lalu Lintas (6 buah)

Tanaman Peneduh (11 buah)

6 Area Pemisah Jalan dengan Trotoar 1.7

meter

Sumber: Hasil survey lapangan, 2017

Dapat dilihat bahwa hampir secara keseluruhan kondisi fisik trotoar di Taman Tingkir sudah sesuai dengan standar keamanan dan kenyamanan yang telah ditetapkan oleh pemerintah. Namun ada sedikit kekurangan dalam kelengkapan fasilitas trotoar seperti belum adanya lampu penerangan, tempat sampah, dll.

Hasil Data Pengguna

Data pengguna yang dimaksud adalah jumlah pejalan kaki di trotoar Taman Tingkir. Proses pengamatan dilakukan selama 1 jam dalam interval waktu 15 menitan dan dilakukan sebanyak 3 kali dalam waktu satu hari yaitu pada pagi, siang dan sore hari. Karena trotoar Taman Tingkir terbagi menjadi 4 bagian, maka pengamatan dilakukan di 4 sisi taman yang berbeda. Data yang terkumpul dari masing-masing bagian trotoar akan diakumulasikan sehingga diperoleh hasil sebagai berikut :

Tabel 6. Tabel volume pejalan kaki di trotoar Taman Tingkir

No Waktu Pengamatan Rata -Rata

Pejalan Kaki tiap 15 menit (orang/15 menit/mtr) Rata -Rata Pejalan Kaki tiap menit (orang/menit/mtr)

$1 \quad 07.00-08.00 \quad 496 \quad 33$

$2 \quad 11.00-12.00 \quad 425 \quad 28$

$3 \quad 15.00-16.00 \quad 634 \quad 42$

Volume Rata -Rata Pejalan Kaki tiap menit dalam 1 hari 34 orang/ menit/mtr

Sumber: Hasil survey lapangan, 2017

Bedasarkan tabel diatas, dihitung lebar minimum trotoar Taman Tingkir adalah :

$\mathrm{W}=\mathrm{V} / 35+\mathrm{N}$

$\mathrm{W}=34 / 35+1$

$\mathrm{W}=1,97$ meter

Apabila mengacu pada dimensi eksisting fisik trotoar yaitu 3.1 meter, maka lebar tersebut sudah mencukupi apabila dikaitkan dengan lebar minimum berdasarkan penghitungan volume rata-rata pejalan kaki yang menggunakan trotoar tersebut.

- Hasil Data Pemanfaatan

Telah dilakukan survey lapangan untuk melihat apakah ada jenis pemanfaatan selain untuk pejalan kaki yang dilakukan di trotoar Taman Tingkir. Survey ini dilakukan di 4 sisi trotoar yang berbeda. Dari hasil survey tersebut, ditemukan ada beberapa jenis 
pemanfaatan yang tidak sesuai dengan peruntukannya baik dilakukan langsung diatas trotoar maupun di sisi trotoar. Adapun pemanfaatan lain di trotoar Taman Tingkir adalah sebagai berikut:

Tabel 7. Tabel pemanfaatan lain di trotoar Taman Tingkir

No Jenis Pemanfaatan Trotoar Jumlah Dampak

1 Pedagang Kaki Lima $20 \quad$ PKL

Berkurangnya lebar efektif trotoar dari 3.10 meter menjadi 1.40 meter

2 Penyewaan Mainan Anak-Anak 15

Penyewaan mainan anak-anak Berkurangnya

lebar efektif trotoar dari 3.10 meter menjadi 1.20 meter

3 Parkir Liar 20 sepeda motor

12 mobil Mengurangi keamanan dan kenyamanan pejalan kaki

Sumber: Hasil survey lapangan, 2017

Gambar 2\&3. PKL dan penyewaan mainan anak di Taman Tingkir kota Salatiga

Sumber: Hasil survey lapangan, 2017

Setelah berbagai observasi lapangan dilakukan, dapat dilihat dari hasil diatas bahwa kondisi eksisting fisik trotoar Taman Tingkir sudah sesuai dengan standar yang ditentukan oleh pemerintah. Hal ini dapat dilihat dari lebar trotoar 3.10 meter yang sudah mencukupi untuk lebar minimum trotoar 1.97 meter dari hasil penghitungan volume pejalan kaki di trotoar tersebut, tinggi kereb 20 centimeter, tinggi bebas trotoar diatas 2.5 meter, serta penggunaan batu andesit bakar dan koral sikat yang kuat dan tidak licin sebagai material penutup trotoar tersebut. Yang menjadi kekurangan pada fisik trotoar Taman Tingkir adalah dalam hal kelengkapan fasilitas/street furniture. Sayangnya kekurangan ini pun diperparah dengan adanya bentuk pemanfaatan lain diatas trotoar Taman Tingkir. Kehadiran pedagang kaki lima(PKL), penyewaan mainan anak, serta parkir liar otomatis berdampak pada berkurangnya ruang gerak pejalan kaki. Trotoar yang awalnya memiliki lebar 3.10 meter, sekarang hanya menjadi 1.20 - 1.40 meter karena digunakan sebagai tempat untuk mendirikan kios PKL dan parkir mainan anak-anak.

2. Hasil Kuesioner dan Wawancara

\section{- Hasil Kuesioner}

Melalui kuesioner yang telah diisi oleh responden baik yang merupakan pejalan kaki yang rutin lewat maupun pejalan kaki yang baru pertama kali atau jarang lewat di trotoar Taman Tingkir, diperoleh hasil sebagai berikut: Tabel 8. Tabel hasil penilaian kuesioner di trotoar Taman Tingkir

\begin{tabular}{|c|c|c|c|c|}
\hline \multirow[t]{2}{*}{ No } & Parameter & Tota & Penilaian & Responden \\
\hline & \multicolumn{4}{|c|}{ Total Nilai Tertinggi } \\
\hline 1 & Lebar trotoar & 72 & 240 & \\
\hline 2 & Tinggi Kereb & 184 & 240 & \\
\hline 3 & \multicolumn{2}{|c|}{ Tinggi Ruang Bebas } & 202 & 240 \\
\hline
\end{tabular}




\begin{tabular}{|c|c|c|}
\hline 4 & Permukaan Trotoar & 177 \\
\hline 5 & Kelancaran Sirkulasi & 73 \\
\hline 6 & Ketersediaan Shelter & 85 \\
\hline 7 & Ketersediaan Barier & 77 \\
\hline 8 & Kebersihan Trotoar & 75 \\
\hline 9 & Keindahaan Trotoar & 81 \\
\hline 10 & Fasilitas Street Furniture & 86 \\
\hline Tot & ai Keseluruhan 1112 & 2400 \\
\hline
\end{tabular}

Sumber: Hasil Analisis, 2017

Dari data diatas, maka diperoleh total penilaian oleh responden sebesar 1112. Lalu untuk total nilai tertinggi kuesioner sebesar 2400. Dari kedua data tersebut, akan dilakukan penilaian menggunakan Rumus Index \%. Penilaiannya adalah sebagai berikut :

Rumus Index $\%=$ Total Penilaian Responden / Total Nilai Tertinggi X 100\%

$$
=1112 / 2400 \times 100 \%
$$

$=46.3 \%=46 \%$ kategori Tidak Aman dan Nyaman

Berdasarkan hasil penghitungan dapat dilihat bahwa dari penilaian responden, trotoar di Taman Tingkir kota Salatiga masuk dalam kategori Tidak Aman dan Nyaman.

\section{- Hasil Wawancara}

Wawancara ini dilakukan guna memperkuat hasil data kuesioner. Dari beberapa pertanyaan yang telah dilontarkan kepada para responden, sebagian besar dari mereka menyatakan bahwa sebenarnya trotoar di Taman Tingkir sudah cukup aman karena material permukaan trotoar yang digunakan sudah kuat dan tidak licin, tinggi trotoar dari jalan raya sudah cukup, serta terdapat pula area pemisah antara jalan dengan trotoar guna menghindari kendaraan bermotor naik diatas trotoar. Hal yang menjadi permasalahan di trotoar Taman Tingkir menurut para responden adalah dari faktor kenyamanan. Adanya pedagang kaki lima(PKL), dan penyewaan mainan anak diatas trotoar serta parkir liar kendaraan di area pemisah jalan dengan trotoar Taman Tingkir, sangat mengganggu kelancaran sirkulasi pejalan kaki. Dengan adanya PKL ini pula, trotoar Taman Tingkir menjadi kotor dan bahkan ada beberapa bagian permukaan trotoar yang rusak karena digunakan sebagai tempat mendirikan kios.

Dari hasil data kuesioner serta wawancara diatas, dapat disimpulkan bahwa trotoar Taman Tingkir sudah cukup aman namun tidak nyaman. Selain dilihat dari hasil kuesioner yang memperlihatkan total penilaian responden terhadap indikator-indikator keamanan lebih baik daripada indikator kenyamanan, hasil wawancara pun juga menyatakan bahwa sebagian besar pejalan kaki merasa tidak nyaman berjalan diatas trotoar Taman Tingkir. Kehadiran PKL, penyewaan mainan anak, serta parkir liar menjadi faktor utama ketidaknyamanan pejalan kaki karena berdampak pada kelancaran sirkulasi serta menyebabkan trotoar Taman Tingkir menjadi kotor dan tidak indah.

\section{KESIMPULAN DAN SARAN}

Hasil penelitian ini menunjukan bahwa dari segi kondisi fisik, trotoar di Taman Tingkir kota Salatiga masuk dalam kategori aman dan nyaman karena sudah sesuai dengan standar-standar ketentuan keamanan dan kenyamanan trotoar yang telah ditetapkan oleh pemerintah. Namun berdasarkan kuesioner dan wawancara kepada para responden dan narasumber yang notabene merupakan pejalan kaki di trotoar 
Taman Tingkir, didapatkan hasil bahwa trotoar Taman Tingkir tidak aman dan nyaman. Penyebab utamanya karena adanya penyalahgunaan fungsi trotoar sebagai tempat pedagang kaki lima, dan penyewaan mainan anak. Ditambah lagi dengan digunakannya area pembatas jalan dengan trotoar sebagai tempat parkir liar. Selain berpengaruh kepada keamanan dan kelancaran sirkulasi pengguna jalan, penyalahgunaan fungsi trotoar ini juga mengganggu kebersihan serta merusak keindahan trotoar di Taman Tingkir kota Salatiga.

\section{REFERENSI}

Gunawan, Wibowo, MSP. 1988. Standart Perancangan Geometrik Jalan Perkotaan. Direktorat Jenderal Bina Marga - Departemen Pekerjaan Umum. Jakarta.

Hakim, R. dan Utomo, H. 2003. Komponen Perancangan Arsitektur Lansekap. Bumi Aksara. Jakarta.

Hakim, R. 2006. Rancangan Visual Landsekap Jalan panduan estetika dinding penghalang kebisingan. PT.Bumi Aksara. Jakarta.

Maslow, A. 1968. Toward a Psychology of Being. Start Publishing LLC.

Rubenstein, Harvey, M. 1987. Central City Mall, a Wiley Intercience Publication. NewYork

Rubenstein, Harvey, M. 1992. Pedistrian Malls Streetscapes, and Urban Spaces. New York.

Unterman, R. 1984. The Pedestrian and The Bysiclist.

Departemen Pekerjaan Umum No.22/T/BM/1999 tentang Pedoman Teknik Persyaratan
Aksesibilitas Pada Jalan Umum. PT. Mediatama Saptakarya. Jakarta.

Direktorat Jendral Bina Marga No. 007/T/BNKT/1990 tentang Petunjuk Perencanaan Trotoar. Jakarta.

Direktorat Jendral Bina Marga No. 011/T/Bt/1995 tentang Tata Cara Perencanaan Fasilitas Pejalan Kaki di Kawasan Perkotaan. Jakarta.

Direktorat Jendral Bina Marga No.032/T/BM/1999 tentang Pedoman Perencanaan Jalur Pejalan Kaki Pada Jalur Jalan Umum. PT. Mediatama Saptakarya. Jakarta.

Keputusan Menteri Perhubungan No. KM 65 tahun 1993 tentang Fasilitas Pendukung Kegiatan Lalu Lintas dan Angkutan Jalan. Jakarta. 